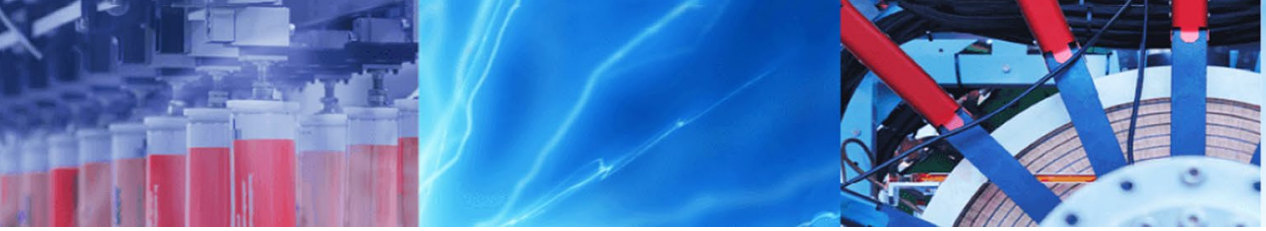

Research Article

\title{
Removal of hazardous basic dyes from aqueous solution by adsorption onto kaolinite and acid-treated kaolinite: kinetics, isotherm and mechanistic study
}

\author{
G. K. Sarma ${ }^{1,3} \cdot$ S. Sen Gupta $^{2} \cdot$ K. G. Bhattacharyya ${ }^{1}$ \\ () Springer Nature Switzerland AG 2019
}

\begin{abstract}
Presence of dye molecules in water causes various harmful effects for both human and aquatic species. Herein, we tried to remove two cationic dyes, namely Crystal violet and Brilliant green, from water by kaolinite clay mineral. The kaolinite clay mineral is further treated with $0.25 \mathrm{M}$ and $0.05 \mathrm{M} \mathrm{H}_{2} \mathrm{SO}_{4}$ to increase its adsorption capacity. The structural changes due to acid treatment were analyzed by XRD, zeta potential, FTIR, SEM, cation exchange capacity, BET surface area, and pore volume measurements. Kinetic data were analyzed by using five different kinetic models and the data fitted best to pseudo-second-order model. Langmuir isotherm showed best fit to the adsorption of both Crystal violet and Brilliant green. Acid-treatment has slightly increased the adsorption capacities for both the dyes. The Langmuir monolayer adsorption capacity of raw kaolinite was found to be 47.17 and $25.70 \mathrm{mg} \mathrm{g}^{-1}$ for Crystal violet and Brilliant green, respectively, which increased to 49.50 and $50.51 \mathrm{mg} \mathrm{g}^{-1}$ for $0.25 \mathrm{M}$ and $0.50 \mathrm{M}$ acid-treated kaolinite in case of Crystal violet and to 26.45 and $26.88 \mathrm{mg} \mathrm{g}^{-1}$ in case of Brilliant green at $303 \mathrm{~K}$. Crystal violet adsorption was exothermic with increase in $\Delta G$ values, whereas Brilliant green adsorption was endothermic in nature with decrease in $\Delta G$ in the temperature range 293-323 K. Reusability study showed the adsorbents could be successfully used up to 3 rd cycle without much loss of adsorption capacity.
\end{abstract}

Keywords Acid treatment $\cdot$ Adsorption $\cdot$ Brilliant green $\cdot$ Crystal violet $\cdot$ Waste water

\section{Introduction}

The world is facing scarcity of clean water due to the pollution caused by various industrial activities. Out of all the various pollutants, one important class is dyes and pigment as they are widely used in various industries like textile, paper, paint etc. Roughly, 1.6 million tons of dyes are produced annually to meet the worldwide demand for dyes and pigments [1]. Unused dyes and pigment released into the water bodies as wastewater are considered major environmental concerns as dyes impart undesirable color to water, reduce light penetration, undergo oxidation and reduction in the aqueous system further producing other toxic and hazardous intermediates, and thereby adversely impact the water ecosystem [2-4]. Because of their low biodegradability, dyes are not easily removed from water by the conventional biological oxidation process [5]. Among other water treatment technique, adsorption process is very popular among researchers due to high Electronic supplementary material The online version of this article (https://doi.org/10.1007/s42452-019-0216-y) contains
supplementary material, which is available to authorized users.

G. K. Sarma, gautamsarma7@gmail.com | 'Department of Chemistry, Gauhati University, Guwahati, Assam 781014, India. ${ }^{2}$ Department of Chemistry, B N College, Dhubri, Assam 783324, India. ${ }^{3}$ Present Address: Department of Chemistry, Rajiv Gandhi University, Doimukh, Arunachal Pradesh 791112, India.

SN Applied Sciences (2019) 1:211 | https://doi.org/10.1007/s42452-019-0216-y

Received: 14 October 2018 / Accepted: 24 January 2019 / Published online: 4 February 2019 
efficiency, easy and simple operation, easy recovery and availability of wide variety of adsorbent materials $[1,6]$.

Activated carbon is the most widely used commercial adsorbent. However, due to its high cost, its widespread use is limited especially in developing countries. To overcome this problem, researchers have always tried to develop low-cost alternative adsorbents [7]. Clay minerals have gained lots of attention from scientific communities as adsorbents or catalyst and biomaterials due to their properties like large surface area, considerable cation exchange capacity (CEC), the presence of both Bronsted and Lewis acidity and its low cost $[8,9]$. Among the clay minerals, however, montmorillonite and bentonite have received the most attention. Therefore, there are lots of scope for exploration of kaolinite clay mineral as an adsorbent. Pauling [10] was the first to outline the crystal structure of kaolinite using model based on idealized polyhedral, and Gruner [11] reported the first structural interpretation of kaolinite powder XRD pattern. The clay minerals in this group consist of dioctahedral 1:1 layer structures with a general composition of $\mathrm{Al}_{2} \mathrm{Si}_{2} \mathrm{O}_{5}(\mathrm{OH})_{4}$. The composition of the kaolin group minerals is characterized by a predominance of $\mathrm{Al}^{3+}$ in octahedral sites, although some isomorphous substitution of $\mathrm{Mg}^{2+}, \mathrm{Fe}^{3+}$, $\mathrm{Ti}^{4+}$ and $\mathrm{V}^{3+}$ for $\mathrm{Al}^{3+}$ can occur [12].

Earlier, kaolinite clay mineral has been used for removal of pollutant from the water. For example, iron-manganese oxide-coated kaolinite was successfully used to remove Basic fuchsin and Crystal violet dyes from water [13]. Removal of Direct red 81 can be effectively carried out with magnesium oxide-coated kaolinite [14]. Zhang et al. [15] used modified kaolinite (kaolinite monolayer grafted with 3-aminopropyl triethoxysilane) for removal of Congo red from water. Removal of Methylene blue and $\mathrm{Cu}(\mathrm{II})$ has been reported by using EDTA modified bentonite [16].

Among other clay mineral modification techniques, acid activation is one of the most common, easy and effective chemical treatment of clays, where the clay is treated with a mineral acid like $\mathrm{HCl}$ or $\mathrm{H}_{2} \mathrm{SO}_{4}$ to obtain partly dissolved amorphous Si-rich phase with less impurity. In our previous study, acid-treated kaolinite showed very good adsorption capacity for dyes like Methylene blue [17], Congo red [18] and Rhodamine B [19] from the water.

In this paper, we tried to remove two different dyes with the help of kaolinite and its acid-treated forms from water with detailed kinetics, isotherm, and thermodynamic properties. Both the studied dye, namely Brilliant green and Crystal violet, are classified as cationic triphenylmethane dye. One of the main reasons to study the adsorption of these two similar dyes is to understand the effect of dye molecule size in the adsorption mechanism. Also, these dyes are considered carcinogenic and are widely used in textile industries. Therefore, treatment of wastewater containing such dyes is of utmost important before that wastewater can enter into a natural water source. The antimicrobial, antiparasitic and antifungal properties of Brilliant green have been found useful in aquaculture to treat various fish diseases. Brilliant Green is reported to have toxic and mutagenic effects on aquatic biota and humans, and the dye is not authorized to be used in fish destined for human consumption in countries like the USA and the European Union. Nevertheless, it is being continuously abused as an antimicrobial agent due to low production cost and high efficacy in the treatment of fish diseases [20-23]. In some recent work, various adsorbent like Tunisian smectite clay [24], biopolymers composites with peanut hull waste biomass [25], magnetic $\mathrm{Fe}_{3} \mathrm{O}_{4} @ S D B S @ L D H s$ composites [26] and surfactant-modified nano- $\gamma$-alumina [27] were used to remove Brilliant green and Crystal violet dyes from water.

\section{Experimental section}

\subsection{Acid treatment of the clay mineral}

The acid-treated kaolinite clay minerals were prepared by slightly modifying a conventional acid treatment method used by Espantaleón et al. [28]. In this study, the Kaolinite, KGa-1b (K) (University of Missouri-Columbia, Source Clay Minerals Repository, USA), clay mineral (20.0 g) was agitated with $200 \mathrm{~mL}$ of $0.25 \mathrm{M} \mathrm{H}_{2} \mathrm{SO}_{4}$ in 250 -mL Erlenmeyer flasks in a thermostatic water bath shaker (NSW, Mumbai, India) for $3 \mathrm{~h}$. The treated clay mineral was collected with centrifugation at 12,000 rmp (Remi R 24 centrifuge), washed three times with distilled water to remove the excess acid and finally collected by centrifugation. The collected clay mineral was dried in an air oven at $383 \mathrm{~K}$ until constant weight and stored in desiccator till further use. The $0.25 \mathrm{M} \mathrm{H}_{2} \mathrm{SO}_{4}$-treated product was designated as sample K1. A similar set of acid modification was carried out with $0.50 \mathrm{M} \mathrm{H}_{2} \mathrm{SO}_{4}$ and is designated as $\mathrm{K} 2$. All the raw and acid-treated kaolinites were characterized by different spectroscopic, microscopic and diffractometric techniques. The details of the characterization techniques are provided in Supporting Information (SI).

\subsection{Dye solution}

Brilliant green $\left(\mathrm{C}_{27} \mathrm{H}_{33} \mathrm{~N}_{2} \cdot \mathrm{HSO}_{4}\right)$ (CAS number: 633-03-4, FW 482.69) and Crystal violet $\left(\mathrm{C}_{25} \mathrm{H}_{30} \mathrm{~N}_{3} \mathrm{Cl}\right)(\mathrm{Cl}$ Classification number: 42555; CAS number: 548-62-9) were obtained from Merck (India) and Qualigens (India), respectively, and used without further purification. The structure of both the dyes was optimized using the density functional theory with Becke's three parameter exchange functional along with the 
Lee-Yang-Parr nonlocal correlation functional (B3LYP) and using 6-31G(d) basis sets as implemented in the Gaussian 09 program package [29]. The structure and its dimension are shown in Fig $\mathrm{S} 1$ (in SI). For adsorption study, a stock solution of both the dyes was prepared separately by dissolving $1 \mathrm{~g}$ of a dye molecule in $1000 \mathrm{~mL}$ of double distilled water. Solutions for the experiments were made from this stock solution by appropriate dilution. The $\mathrm{pH}$ of an aqueous solution of Brilliant green is found to be 5.4, and the same for Crystal violet dye is 5.9. We observed that, for aqueous solution, both the dye solution changes color when the $\mathrm{pH}$ of the medium is changed. Around $\mathrm{pH} 6.0$, the aqueous solution of Brilliant green dye develops some amount of turbidity, which increases further with an increase in $\mathrm{pH}$. Crystal violet, on the other hand, changes its color to bluish green at $\mathrm{pH}<3.0$. But at $\mathrm{pH} \sim 11.0$, it becomes almost colorless [30].

\subsection{Adsorption experiments}

The adsorption of dye molecules in kaolinite clay minerals and its acid-modified forms was carried out in batch adsorption mode. Here, a fixed amount of the respective clay minerals were mixed with $50 \mathrm{ml}$ aqueous solution of dye solution of fixed concentration in a 100-ml Erlenmeyer flask. The Erlenmeyer flask was then shaken in a thermostatic water bath shaker (NSW, Mumbai, India) at a constant speed for a predetermined time interval. Finally, the mixture was centrifuged for $15 \mathrm{~min}$ (Remi R 24, 8000 rpm) and the dye remaining unadsorbed in the supernatant liquid was determined spectrophotometrically (Elico SL 177, India). The experimental data were reported based on average of three sets of experiments. The amount of the dye adsorbed per unit mass of the adsorbent $\left(q_{\mathrm{e}^{\prime}} \mathrm{mg} \mathrm{g}^{-1}\right)$ and the extent of adsorption (\%) were computed from the expressions:

$q=\left(C_{0}-C_{t}\right) / m$

$\%$ adsorption $=\left(C_{\mathrm{o}}-C_{t}\right) \times 100 / C_{\mathrm{o}}$ where $C_{\mathrm{o}}\left(\mathrm{mg} \mathrm{L}^{-1}\right)$ and $C_{t}\left(\mathrm{mg} \mathrm{L}^{-1}\right)$ are the initial dye concentration and that after adsorption on $m(\mathrm{~g})$ of the adsorbent in $1 \mathrm{~L}$ solution after time, $t(\mathrm{~min})$. Blank experiment without adding the adsorbent was done to find if the wall of the container has any effect on adsorption. The batch adsorption experiments were conducted under different conditions.

\section{Results and discussion}

\subsection{Characterization of the clay minerals}

The influence of acid treatment on kaolinite clay mineral was monitored by the changes in XRD patterns (Fig. 1).
The XRD patterns of raw and acid-treated kaolinite can be indexed to (001), (110), (002), (130), (003), (-110), (150) and (060) planes of kaolinite (PDF no. 29-1488). One strong peak at $2 \theta=44.6$ corresponding to d value $2.01 \AA$ (Asterisk in Fig. 1) could be assigned to the mineral Halloysite-7A (PDF No 09-0453). Acid treatment had some influence on the $d$-spacing of (001) plane of kaolinite, which expanded slightly to 7.16 in case of K1 and $7.17 \AA$ in K2. Acid treatment also resulted in changes in the intensity of most of the XRD bands with either a decreasing or an increasing trend-an indication that the acid treatment changed the lattice order along the $c$ axis [31]. Acid treatment is normally thought to be responsible for amorphization of the clay mineral which is accompanied by a decrease in the intensities of the diffraction peaks [32]. In this work, decreased intensity (from 87.51 to $56.52 \%$ ) in the 001 planes was observed in acid-treated kaolinite; however, changes in intensities for other peaks were irregular and no definite trends could be identified. The intensity of the band due to halloysite-7A found on kaolinite decreased significantly after acid treatment of $0.5 \mathrm{M}$ acid compared to $0.25 \mathrm{M}$ acid, indicating that these minerals were present as surface impurities and a higher concentration of acid could remove them quite effectively. XRD measurements revealed that the structural integrity of the kaolinite clay mineral basically remained unchanged. The low concentration of acid used in this study mainly cleaned the surface for higher adsorption without damaging the clay mineral structure. It has been observed before that acid strength of less than $2 \mathrm{M}$ does not do any significant structural damage to the clay minerals [33]. The average grain size $\left(D_{c}\right)$ of the prepared materials was calculated to be $32.6 \mathrm{~nm}, 40.5 \mathrm{~nm}$ and $32.7 \mathrm{~nm}$ for $\mathrm{K}, \mathrm{K} 1$ and $\mathrm{K} 2$, respectively, with the help of width of the lines in the XRD

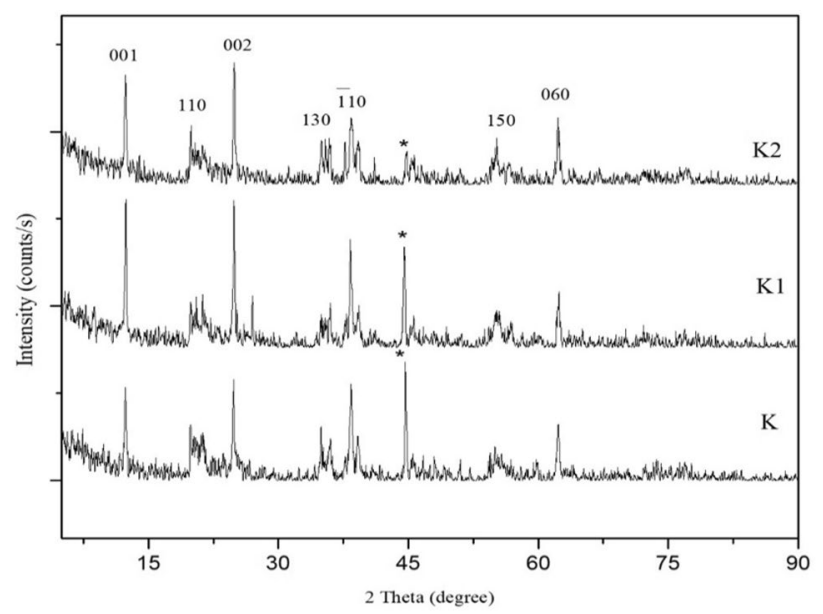

Fig. 1 XRD patterns of Kaolinite (K), $0.25 \mathrm{M}$ acid-treated Kaolinite (K1) and 0.50 M acid-treated Kaolinite (K2) 
spectrum with the aid of the Scherrer equation: $D_{c}=k \lambda$ / $(\beta \cos \theta)$, where $\lambda$ is the wavelength of $\mathrm{X}$-ray used ( $\mathrm{Cu} \mathrm{Ka}$ radiation $\lambda=0.1541 \mathrm{~nm}$ ), $\beta$ is the width of the line at the half maximum intensity and $k$ a constant, 0.89 [34].

The FTIR bands of raw and acid-treated kaolinite clay minerals are shown in Fig S2 (In SI). The peak at $3618 \mathrm{~cm}^{-1}$ shown by kaolinite was due to $-\mathrm{OH}$ stretching in the inner hydroxyl group lying between the tetrahedral and octahedral sheets and the band observed at $3695 \mathrm{~cm}^{-1}$ was due to the contribution of the hydroxyl groups sitting at the edges of the clay platelets $[35,36])$. $-\mathrm{OH}$ bending vibration and $\mathrm{Al}-\mathrm{O}-\mathrm{H}$ deformation vibration mode was observed at 1654 and $914 \mathrm{~cm}^{-1}$. O-Si-O stretching and deformation modes were observed at 1006, 1029 and $1114 \mathrm{~cm}^{-1}$. The bands at 428,470 and $536 \mathrm{~cm}^{-1}$ could be assigned to $\mathrm{Si}-\mathrm{O}-\mathrm{Si}, \mathrm{Si}-\mathrm{O}-\mathrm{Mg}$ and $\mathrm{Si}-\mathrm{O}-\mathrm{Al}$ respectively [37]. The band at $790 \mathrm{~cm}^{-1}$ confirmed the presence of amorphous silica in the clay minerals [38].

In this work, the intensities of all the major bands decreased and in some cases a little broadening of the peaks was observed after acid treatment, indicating that there was depletion in the concentrations of the octahedral cations $\left(\mathrm{Al}^{3+}, \mathrm{Fe}^{3+}, \mathrm{Mg}^{2+}\right)$ which might have been replaced by protons [38, 39]. Nguetnkam et al. [31] identified this decrease in intensities due to the amorphization of the clay mineral due to acid treatment, leading to the formation of amorphous silica.

As a whole, FTIR analysis indicated that acid treatment affects the clay mineral surface without altering the basic clay mineral structure. The acid treatment made the clay mineral surface more protonated.

The SEM images for kaolinite clay minerals are shown in Fig. 2. It was observed that kaolinite was composed of hexagonal flakes of different size and broken edges. The flakes also possessed some white deposits on them. Other workers have observed such deposits consisting of oxides of sodium, potassium, calcium, iron, magnesium, etc. [40, 41].

Acid treatment has broken down most of the bigger particles to the size of $2 \mu \mathrm{m}$ or less but has retained the flaky nature of the particle. Acid activation also removed most of the white deposits. With $0.05 \mathrm{M}$ acid, most of the non-clay deposits on the clay particles appeared to have been removed and the surface became homogeneous and clean. Irregularity in size and shape of the particles remained and the damages to the edges became clearer.

The $\mathrm{N}_{2}$ adsorption/desorption isotherms of the raw and acid-treated kaolinite are shown in Fig. 3. Kaolinite and its acid-treated forms showed Type II isotherm according to IUPAC recommendation. Generally, type II isotherm is the normal form of isotherm obtained with a non-porous or macroporous adsorbent. The Type II isotherm represents unrestricted monolayer-multilayer
$(\mathrm{K})$

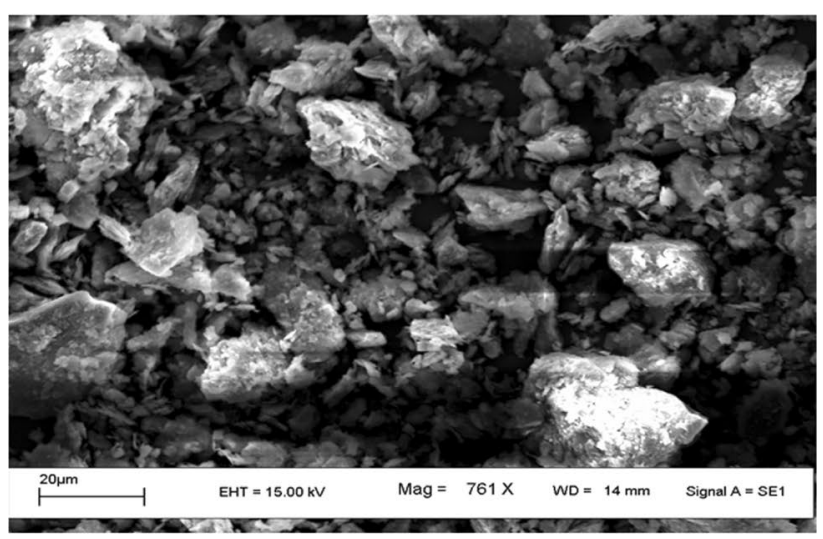

(K1)

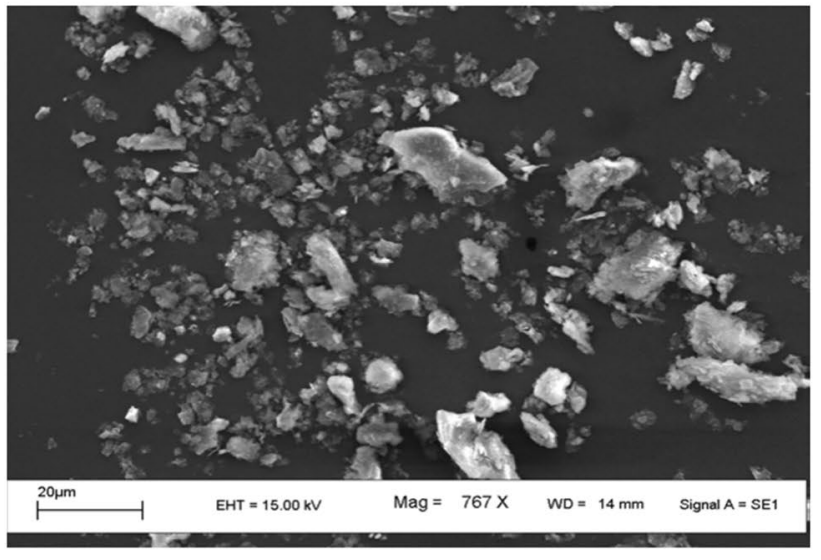

(K2)

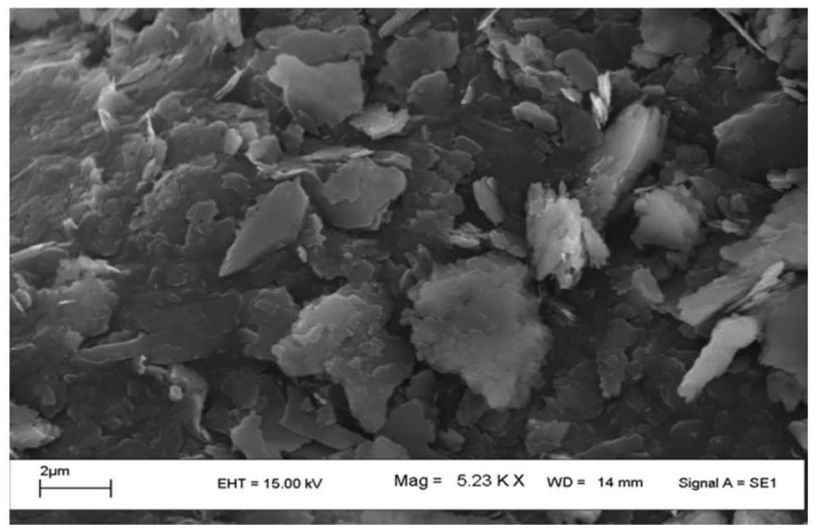

Fig. 2 SEM images of kaolinite (K), $0.25 \mathrm{M}$ acid-treated kaolinite (K1) and 0.50 M acid-treated kaolinite (K2)

adsorption [42]. Kaolinite clay mineral used in this study showed BET surface area of $14.39 \mathrm{~m}^{2} \mathrm{~g}^{-1}$ (Table 1), which increased marginally to 15.27 and $15.68 \mathrm{~m}^{2} \mathrm{~g}^{-1}$ on treatment with $0.25 \mathrm{M}$ and $0.50 \mathrm{M}$ acid, the increase in the surface area is only 6.1 and $9.0 \%$, respectively. Although the pore volume was much lower, the increase in pore volume following acid treatment was tremendous, $\sim 2$ 
(a)

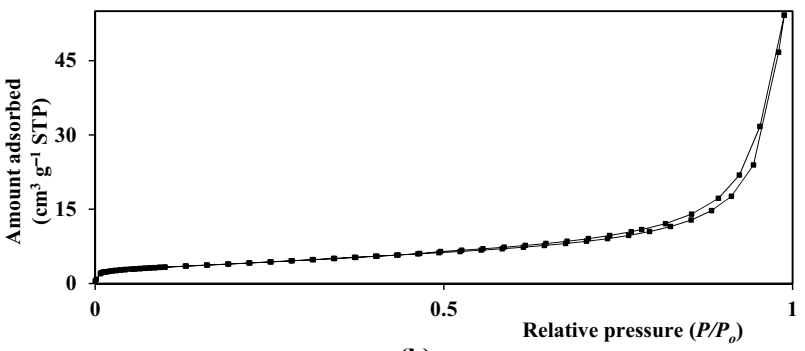

(b)

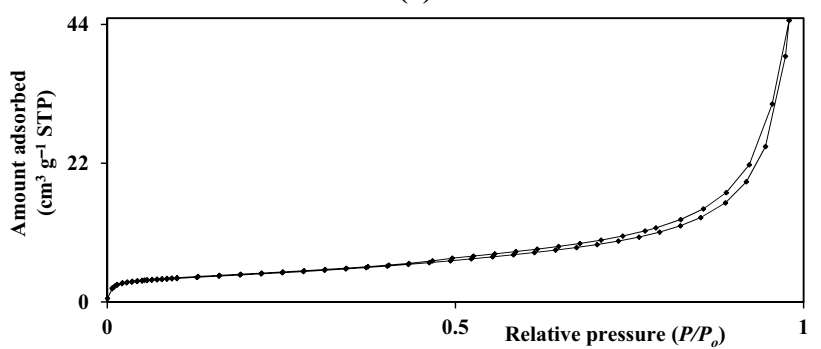

(c)

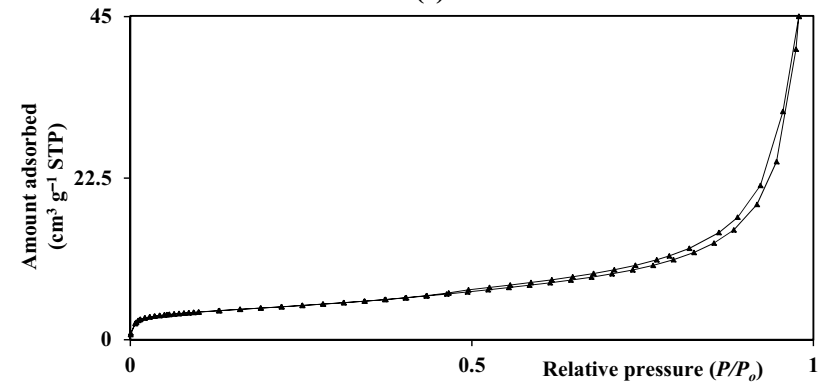

Fig. 3 BET linear isotherm $\mathrm{N}_{2}$ gas adsorption-desorption plot for a Kaolinite (K), b $0.25 \mathrm{M}$ acid-treated Kaolinite (K1) and c $0.50 \mathrm{M}$ acidtreated Kaolinite (K2)

Table 1 Surface and pore characteristics of kaolinite (K) and the acid-treated kaolinites (K1 and K2)

\begin{tabular}{llll}
\hline Clay minerals & $\begin{array}{l}\text { BJH Pore diam- } \\
\text { eter }(\mathrm{nm})\end{array}$ & $\begin{array}{l}\text { Total pore vol- } \\
\text { ume }\left(\mathrm{cm}^{3} \mathrm{~g}^{-1}\right)\end{array}$ & $\begin{array}{l}\text { BET surface } \\
\text { area } \\
\left(\mathrm{m}^{2} \mathrm{~g}^{-1}\right)\end{array}$ \\
\hline $\mathrm{K}$ & 8.99 & 0.0053 & 14.39 \\
$\mathrm{~K} 1$ & 8.69 & 0.0103 & 15.27 \\
$\mathrm{~K} 2$ & 7.21 & 0.0584 & 15.68 \\
\hline
\end{tabular}

and $>10$ times for $0.25 \mathrm{M}$ and $0.50 \mathrm{M}$ acid-treated kaolinite. The acid has thus served to increase the porous character of the clay mineral.

The distribution curves for $\mathrm{BJH}$ pore volume with pore diameter for the kaolinites are shown in Fig $\mathrm{S} 3$ (in $\mathrm{SI}$ ). The $\mathrm{BJH}$ average pore diameter for kaolinite (K), $0.25 \mathrm{M}$ acidtreated kaolinite (K1) and $0.50 \mathrm{M}$ acid-treated kaolinite (K2) were 8.99, 8.69 and $7.21 \mathrm{~nm}$, respectively (Table 1). The effects of acid treatment on pore volume can be summarized as follows:
1. The increase in pore volume after treatment with $0.25 \mathrm{M}$ acid (Fig. S3a, in $\mathrm{SI}$ ) was not much. It is seen that volumes of pores of all sizes increase by 2-3 times, but the increase was much more for pores of diameter $>12 \mathrm{~nm}$ and the increase followed almost a linear pattern for these larger pores.

2. The increase in pore volume was most prominent for $0.50 \mathrm{M}$ acid-treated kaolinite (Fig. S3b, in SI). There was also a huge increase in pore volume of small pores of diameter, 2.9-3.5 nm and as a whole, all the large pores showed a high linear increase in volume.

3. The pore volume measurement thus showed that although the acid treatment did not have much impact on the overall surface area, the pore volume was affected significantly, particularly in the case of $0.50 \mathrm{M}$ acid treatment. In other words, acid-treatment created a considerable amount of internal volume in kaolinite.

Acid treatment usually opens up smaller pores resulting in increased surface area [43]. Pore size distribution for $K$ and $\mathrm{K} 1$ showed that a few small pores of radii, 3.5, 4.1, 4.9 and $5.7 \mathrm{~nm}$ were more prominent than the others and these pores were almost similarly affected when kaolinite was treated with a mild acid of strength $0.25 \mathrm{M}$. Increasing the acid strength to two times $(0.5 \mathrm{M})$, however, had a much stronger influence on pore size distribution. The material, $\mathrm{K} 2$, now showed a sharp rise in the pore volume for the pores around $3.4 \mathrm{~nm}$ pore radius. It is possible that the relatively strong acid entered deep into the pores in a narrow range of diameters around $3.4 \mathrm{~nm}$ and enhanced the corresponding pore volume. It is to be noted that all higher dimension pores (pore diameter $>6 \mathrm{~nm}$ ) also showed a huge increase in pore volume after treatment with $0.50 \mathrm{M}$ acid. Acid treatment increased the pore volume of kaolinite clay minerals in the order $\mathrm{K} 2>\mathrm{K} 1>\mathrm{K}$. Panda et al. also reported a successive increase in pore volume with increase in acid concentration for $\mathrm{H}_{2} \mathrm{SO}_{4}$ [32]. However, if more drastic acid or thermal treatment was done, generally the well-organized layered structure of the clay is destroyed and the amorphous phase was produced. Gao et al. have activated coal-bearing kaolinite, collected from coal seam deposits in mines in Inner Mongolia, northern China, with concentrated $\mathrm{H}_{2} \mathrm{SO}_{4}$ for fixed time and fixed temperature (obtained product denoted by AAK-T-t; $T$ and $t$ denote the treatment temperature $\left({ }^{\circ} \mathrm{C}\right)$ and the time (min) of treatment, respectively). The authors observed a substantial influence of both time and temperature on the BET surface area, with AAK-RT-30 showing BET surface area of $28.0 \mathrm{~m}^{2} \mathrm{~g}^{-1}$. This increases up to $257.8 \mathrm{~m}^{2} \mathrm{~g}^{-1}$ for AAK-200-30. When the temperature is increased to $250^{\circ} \mathrm{C}$, the BET surface area decreased to $70.3 \mathrm{~m}^{2} \mathrm{~g}^{-1}$. However, a drastic change in XRD pattern with no well-defined peak 
was observed for samples prepared at $220^{\circ} \mathrm{C}$ and $250^{\circ} \mathrm{C}$, indicating the formation of an amorphous phase [44]. In another study, when metakaolinite was treated with $3 \mathrm{M}$ $\mathrm{HCl}$ at $90^{\circ} \mathrm{C}$ for $2 \mathrm{~h}$ and subsequent calcination at $400^{\circ} \mathrm{C}$ $(2 \mathrm{~h})$, the BET surface area increased from 23 to $40 \mathrm{~m}^{2} \mathrm{~g}^{-1}$. But metakaolinite prepared at $900{ }^{\circ} \mathrm{C}$ followed by treatment with $3 \mathrm{M} \mathrm{HCl}$ at $90^{\circ} \mathrm{C}$ for $2 \mathrm{~h}$, the micropore surface area increased up to $526 \mathrm{~m}^{2} \mathrm{~g}^{-1}$. Again this drastic modification leads to the breakdown of the crystalline phases in kaolinite [45]. In the present work, the mild modification process ensured an increase in surface area with no major changes in the crystalline structure of kaolinite.

Acid treatment enhanced the cation exchange capacity (CEC) of kaolinite (K) from 11.3 to 17.2 (K1) and 22.9 (K2) meq/100 g. Thus, acid treatment increased the total number of exchange sites profoundly in kaolinite (CEC increase $~ 34 \%$ in $\mathrm{K} 1$ and $~ 51 \%$ in $\mathrm{K} 2$ ). The increase in CEC with an increase in acid concentration may be due to the replacement of a higher number of cations with $\mathrm{H}^{+}$as the acid concentration increases.

\subsection{Process optimization}

\subsubsection{Influence of $\mathrm{pH}$}

The $\mathrm{pH}$ of the aqueous solution is an important parameter that controlled the adsorption process. The studied dyes, Crystal violet, and Brilliant green showed high sensitivity toward changes in the $\mathrm{pH}$ of the medium.

The effect on adsorption of Brilliant green with $\mathrm{pH}$ variation could not be performed as even a slight change in $\mathrm{pH}$ changes its color. Around $\mathrm{pH} 6.0$, the aqueous solution of the dye develops some amount of turbidity, which increases further with an increase in $\mathrm{pH}$.

For Crystal violet, the study was carried out in the $\mathrm{pH}$ range 4.0-9.0, because, at $\mathrm{pH}<3.0$, the dye solution changes color to bluish violet and at $\mathrm{pH} \sim 11.0$, the solution becomes almost colorless. The effect of the $\mathrm{pH}$ on the adsorption of Crystal violet $\left(100 \mathrm{mg} \mathrm{L}^{-1}\right)$ on kaolinite $(2.0 \mathrm{~g}$ $\mathrm{L}^{-1}$ ) using the batch technique is shown in Fig. 4. Adsorption continuously increased from $\sim 25 \mathrm{mg} \mathrm{g}^{-1}$ at $\mathrm{pH} 4.0$ to $\sim 36 \mathrm{mg} \mathrm{g}^{-1}$ at $\mathrm{pH}$ 9.0. Zeta potential studies showed that Kaolinite has $\mathrm{pH}_{\mathrm{zpc}}$ at 2.9 which increased to 4.0 and 4.2, respectively, for $\mathrm{K} 1$ and $\mathrm{K} 2$ after acid treatment. Hence, at the studied $\mathrm{pH}$ range, the clay mineral surface was mostly negatively charged and as the $\mathrm{pH}$ increased, the surface negativity increased; thus, as expected the adsorption of those cationic dyes increased with increasing $\mathrm{pH}$.

\subsubsection{Influence of adsorbent loading}

For variation of adsorbent loading of $1.0-5.0 \mathrm{~g} \mathrm{~L}^{-1}$ (Brilliant green $50 \mathrm{mg} \mathrm{L}^{-1}, \mathrm{pH}$ 5.4, temperature $303 \mathrm{~K}$, equilibrium

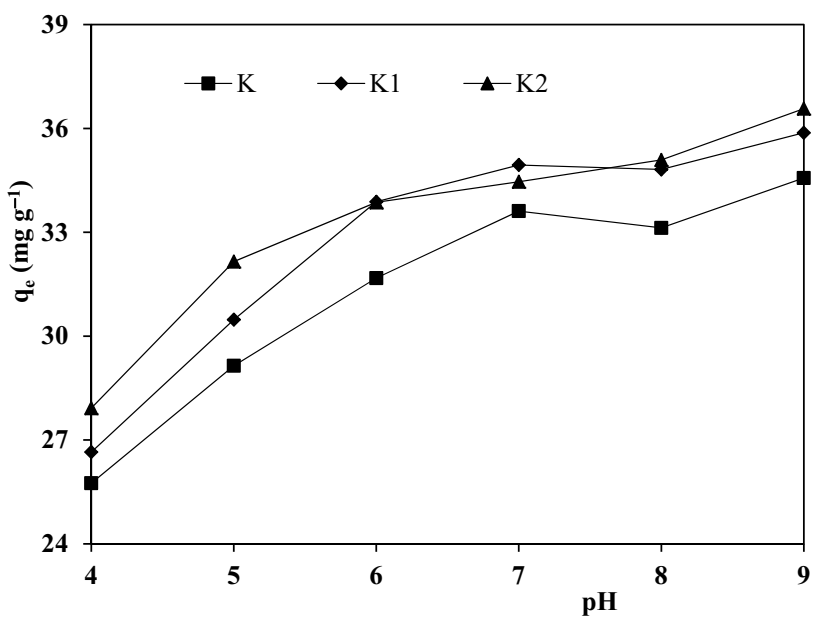

Fig. 4 Effects of $\mathrm{pH}$ on adsorption of Crystal violet $\left(100 \mathrm{mg} \mathrm{L}^{-1}\right)$ on raw and acid-treated kaolinite $\left(2.0 \mathrm{~g} \mathrm{~L}^{-1}\right)$ at $303 \mathrm{~K}$

time $120 \mathrm{~min}$ ) and $1.0-6.0 \mathrm{~g} \mathrm{~L}^{-1}$ (Crystal violet $100 \mathrm{mg} \mathrm{L}^{-1}$, $\mathrm{pH} 5.9$, temperature $303 \mathrm{~K}$, equilibrium time $180 \mathrm{~min}$ ), the uptake of the respective dyes increased from 40.77 to 93.79\% (K), 45.74 to $94.54 \%(\mathrm{~K} 1), 57.27$ to $95.81 \%(\mathrm{~K} 2)$ and from 44.34 to $89.28 \%(\mathrm{~K}), 50.13$ to $90.74 \%$ (K1) and 51.29 to $92.11 \%(K 2)$, respectively. This increase of the extension of adsorption (\%) was the result of enhancement of available adsorption sites. But a decreasing trend was observed for amount adsorbed per unit mass $\left(q_{e}\right)$ with increase in adsorbent loading for both Brilliant green ( $\mathrm{K}: 20.38-7.81 \mathrm{mg} \mathrm{g}^{-1}$, $\left.\mathrm{K} 1: 22.87-7.88 \mathrm{mg} \mathrm{g}^{-1}, \mathrm{~K} 2: 28.63-7.98 \mathrm{mg} \mathrm{g}^{-1}\right)$ and Crystal violet (K: $44.34-14.88 \mathrm{mg} \mathrm{g}^{-1}, \mathrm{~K} 1: 50.13-15.12 \mathrm{mg} \mathrm{g}^{-1}, \mathrm{~K} 2$ : $\left.51.29-15.35 \mathrm{mg} \mathrm{g}^{-1}\right)$. Hence, it can be assumed that some of the adsorption sites were not available for the dye molecules at higher adsorbent loading despite an increase in surface area with an increase in mass. The larger mass might be due to coagulation hinders the approach of the dye molecule to the available adsorption sites, decreasing the adsorption per unit mass even though there was a net increase in the extent of adsorption.

\subsection{Kinetics of adsorption}

Kinetic models can give valuable insight into the adsorption rate and adsorption mechanism [46]. Fig. S4 (in SI) shows the adsorption variation of the dye molecules on both raw and acid-treated clay minerals with time. From the figure, it is clear that adsorption of both Crystal violet and Brilliant green dye occurred through two distinct phases, initially, for about $\sim 10 \mathrm{~min}$, the adsorption process is very fast for both the dye molecules. However, after that, the adsorption continued at a slower pace and reached equilibrium at 180 min for Crystal violet and at $\sim 120$ min for Brilliant green. This might be due to the easily accessible surface 
area of the clay minerals in the initial stage of adsorption. The kinetics data were fitted into various kinetic models, like Lagergren's pseudo-first-order [47], pseudo-second-order $[48,49]$, Elovich model [48], intraparticle diffusion [50] and liquid film diffusion [51] models to establish the most favorable kinetic model in each adsorption case.

\subsubsection{Lagergren's pseudo-first-order kinetics}

The linear pseudo-first-order Lagergren model [47] can be represented by the equation

$\log \left(q_{\mathrm{e}}-q_{\mathrm{t}}\right)=\log q_{\mathrm{e}}-k_{1} t / 2.303$

where $q_{\mathrm{e}}$ and $q_{\mathrm{t}}$ were amounts adsorbed per unit mass at equilibrium and at any time $t$, respectively, $k_{1}\left(\mathrm{~min}^{-1}\right)$ was the first-order rate coefficient. A plot of $\log \left(q_{\mathrm{e}}-q_{\mathrm{t}}\right)$ versus time $(t)$ gave a straight line $(r:-0.99$ for Brilliant green and $r:-0.95$ to -0.98 for Crystal violet at $303 \mathrm{~K}$ ). Brilliant green showed slightly higher first-order rate coefficient $\left(2.4 \times 10^{-2}\right.$ to $\left.2.7 \times 10^{-2} \mathrm{~min}^{-1}\right)$ compared to Crystal violet $\left(1.47 \times 10^{-2}\right.$ to $\left.2.04 \times 10^{-2} \mathrm{~min}^{-1}\right)$. The firstorder mechanism, however, becomes untenable since $q_{e}$ obtained from the plots did not match the experimental values and showed large deviation for both Brilliant green (51.12-56.95\%) and Crystal violet (59.47-66.75\%).

\subsubsection{Pseudo-second-order}

This model is generally followed by adsorption process where chemisorption is the rate controlling step at the solid surface of the adsorbent [52]. The linear pseudo-secondorder kinetic equation $[48,49]$ could be represented by:

$t / q_{t}=1 /\left(k_{2} q_{\mathrm{e}}^{2}\right)+\left(1 / q_{\mathrm{e}}\right) t$

where $q_{\mathrm{e}}$ and $q_{t}$ were amounts adsorbed per unit mass at equilibrium and at any time $t, k_{2}\left(\mathrm{~g} \mathrm{mg}^{-1} \mathrm{~min}^{-1}\right)$ is the pseudo-second-order rate coefficient. The plots of $t / q_{t}$ versus $t$ were linear $(r \sim+0.99$, Fig. 5$)$ for both the dyes with higher pseudo-second-order rate coefficient for Brilliant green $\left(7.3 \times 10^{-3}\right.$ to $\left.9.1 \times 10^{-3} \mathrm{~g} \mathrm{mg}^{-1} \mathrm{~min}^{-1}\right)$ compared to Crystal violet $\left(4.09 \times 10^{-3}\right.$ to $\left.5.05 \times 10^{-3} \mathrm{~g} \mathrm{mg}^{-1} \mathrm{~min}^{-1}\right)$ at $303 \mathrm{~K}$. The experimental $q_{\mathrm{e}}$ values and those obtained from the plots showed very little deviation $(-0.92$ to $+0.09 \%$ for Brilliant green and -1.09 to $+1.92 \%$ for Crystal violet, Table 2), suggesting a pseudo-second-order mechanism for the studied clay-dye interactions.

\subsubsection{Elovich model}

This model assumes that the solid surface of the adsorbent is energetically heterogeneous [53]. The simplified Elovich equation [48] is represented as:

$q_{t}=2.303 \beta \log (\alpha \beta)+2.303 \beta \log t$ (a)
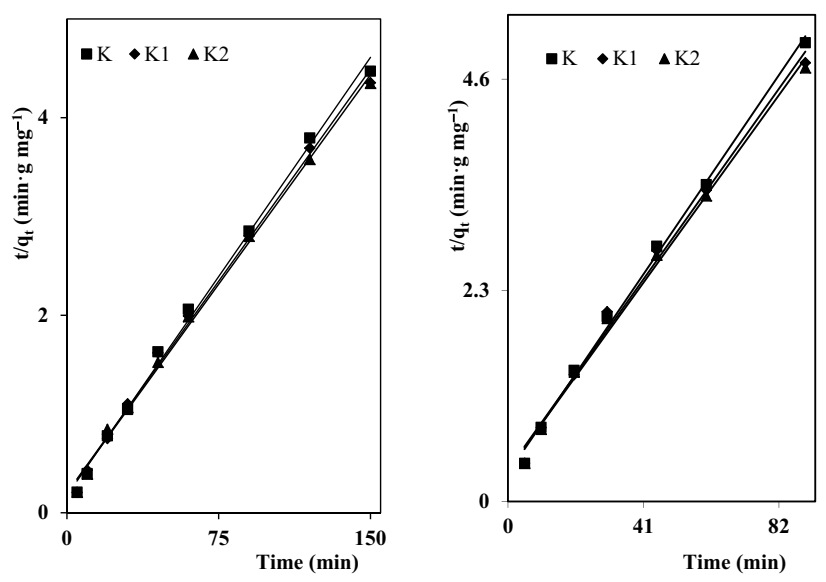

Fig. 5 Second-order plot for a crystal violet $\left(100 \mathrm{mg} \mathrm{L}^{-1}\right)$ and $\mathbf{b}$ brilliant green $\left(50 \mathrm{mg} \mathrm{L}^{-1}\right)$ on raw and acid-treated kaolinite $\left(2.0 \mathrm{~g} \mathrm{~L}^{-1}\right)$ at $303 \mathrm{~K}$

where $q_{t}$ is the adsorption capacity at time $t$, $a$ is the initial adsorption rate $\left(\mathrm{mg} \mathrm{g}^{-1} \mathrm{~min}^{-1}\right)$, and $\beta$ is the desorption constant $\left(\mathrm{g} \mathrm{mg}^{-1}\right)$ during any one experiment. Adsorption of both the dyes on kaolinite and acid-treated kaolinite showed good linearity with $r$ ranging from +0.93 to +0.97 . Thus, this model further supported the earlier conclusion that the interactions were following pseudo-second-order kinetics [54].

\subsubsection{Intraparticle diffusion}

In the batch adsorption technique, since constant shaking is going on between adsorbent and adsorbate, it is very likely that the adsorbate molecules might have difficulty entering into the pores and intraparticle diffusion is unlikely to be the driving force behind adsorption. This is further confirmed by the plots of $q_{t}$ versus $t^{0.5}$ in accordance with the equation [50,55],

$q_{t}=k_{\mathrm{i}} t^{0.5}$

Although the plots at $303 \mathrm{~K}$ were linear for both the cases $(r:+0.96$ to +0.99$)$, they do not fulfill the necessary condition of zero intercepts and therefore, the intraparticle diffusion rate $\left(k_{\mathrm{i}}: 0.90-1.11 \mathrm{mg} \mathrm{g}^{-1} \mathrm{~min}^{-0.5}\right)$ had no real significance.

\subsubsection{Liquid film diffusion}

The dye molecules as adsorbent are quite big in size; therefore, there is a big possibility that it may diffuse very slowly through the liquid film over the clay mineral adsorbent before interacting with the surface active sites of the clay minerals [30]. There is a possibility that the 
Table 2 Second-order rate coefficients for adsorption of Brilliant green (initial dye concentration $50 \mathrm{mg} \mathrm{L}^{-1}$, $\mathrm{pH} 5.4$, temperature $303 \mathrm{~K}$ ) and Crystal violet (initial dye concentration $100 \mathrm{mg} \mathrm{L}^{-1}$; $\mathrm{pH}$ 5.9; temperature $303 \mathrm{~K}$ ) on kaolinite and acid-treated kaolinite $\left(2.0 \mathrm{~g} \mathrm{~L}^{-1}\right)$ at $303 \mathrm{~K}$

\begin{tabular}{|c|c|c|c|c|c|c|}
\hline \multirow[t]{3}{*}{ Clay minerals } & \multirow[t]{3}{*}{ Dye } & \multicolumn{5}{|c|}{ Rate coefficient } \\
\hline & & \multirow{2}{*}{$\begin{array}{l}k_{2} \times 10^{3} \\
\left(\mathrm{~g} \mathrm{mg}{ }^{-1}\right. \\
\left.\min ^{-1}\right)\end{array}$} & \multirow[t]{2}{*}{$r$} & \multicolumn{3}{|l|}{$q_{\mathrm{e}}\left(\mathrm{mg} \mathrm{g}^{-1}\right)$} \\
\hline & & & & Experimental & Plot & Deviation (\%) \\
\hline K & Brilliant green & 9.10 & +0.99 & 18.84 & 18.90 & -0.32 \\
\hline K1 & & 7.40 & +0.99 & 19.58 & 19.76 & -0.92 \\
\hline $\mathrm{K} 2$ & & 7.30 & +0.99 & 20.10 & 20.08 & 0.09 \\
\hline K & Crystal violet & 5.05 & +0.99 & 34.44 & 33.78 & 1.92 \\
\hline K1 & & 4.09 & +0.99 & 34.89 & 34.97 & -0.23 \\
\hline $\mathrm{K} 2$ & & 4.09 & +0.99 & 34.96 & 35.34 & -1.09 \\
\hline
\end{tabular}

film diffusion process might be the rate-determining step, therefore to substantiate that, the plots of-log $(1-F)$ versus $t$ were drawn to validate the liquid film diffusion model [51] represented by the equation:

$\log (1-F)=-k_{\mathrm{fd}} t / 2.303$

( $F$ is the fractional attainment of equilibrium $=q_{t} / q_{\mathrm{e}}, k_{\mathrm{fd}}$ is the diffusion rate coefficient). Both the plots for Brilliant green and Crystal violet showed high linearity $(r:+0.96$ to +0.99 ). However, as required by the model, the curves did not pass through the origin. However, the intercept values were very close to zero for both the cases $(+0.72$ to +0.84 for Brilliant green and +0.90 to +1.10 for Crystal violet), and it might be possible that even though liquid film diffusion was not the sole rate-determining step, it played some role in overall kinetics for both adsorption process. The film diffusion rate coefficient had values in the range of $0.025-0.027 \mathrm{~min}^{-1}$ (for Brilliant green) and $0.015-0.021 \mathrm{~min}^{-1}$ (for Crystal violet) at $303 \mathrm{~K}$.

The kinetics of adsorption for dyes like Brilliant green and Crystal violet on kaolinite and acid-treated kaolinite were not simple, and a particular definite kinetic model could not be proposed. From the above discussion, pseudo-second-order model was found the best fit to the experimental data; however, liquid film diffusion might also play some role in the overall kinetics even though it was not the rate-determining step.

\subsection{Adsorption isotherm}

Adsorption isotherm gives us valuable information regarding the adsorbate-adsorbent interaction, and this information is crucial for optimizing the use of adsorbents [56]. Therefore, many authors have proposed different isotherm models to understand the isotherm equilibrium data. A few of the most common isotherms models having widest applications were fitted with the adsorption equilibrium data to understand the adsorption process.

\section{SN Applied Sciences}

\subsubsection{Freundlich isotherm}

This isotherm model is generally applicable for adsorption of adsorbent on the heterogeneous surface of the adsorbate [57]. The linear form of the Freundlich equation [58] can be represented by:

$\log q_{\mathrm{e}}=\log K_{\mathrm{f}}+(1 / n) \log C_{\mathrm{e}}$

where $C_{\mathrm{e}}$ is the equilibrium concentration of the dye ( $\mathrm{mg}$ $\left.\mathrm{L}^{-1}\right) ; q_{\mathrm{e}}$ is the amount of the dye adsorbed per unit mass $\left(\mathrm{mg} \mathrm{g}^{-1}\right), K_{f}\left(\mathrm{mg}^{1-1 / n} \mathrm{~L}^{1 / \mathrm{n}} \mathrm{g}^{-1}\right)$ and $\mathrm{n}$ are Freundlich coefficients related to adsorption capacity and adsorption intensity, respectively. It is generally accepted that the reciprocal Freundlich intensity $(1 / n)$ is $<1.0$ for favorable adsorption.

At $303 \mathrm{~K}$, the Freundlich isotherm plots for Crystal violet were linear $(r:+0.94$ to +0.98$)$. But the linearity for the Brilliant green dye was not good enough $(r:+0.75$ to +0.91$)$. However, in both adsorption cases, $(1 / n)<1$, indicating favorable adsorption (Table 3 ). Acid treatment showed an increase in adsorption capacity $\left(K_{f}\right)$ in the order $\mathrm{K} 2>\mathrm{K} 1>\mathrm{K}$ for Crystal violet dye. Brilliant green dye did not show any particular trend may be due to poor linearity of the Freundlich plot.

\subsubsection{Langmuir isotherm}

This model was primarily developed to describe adsorption capacities for adsorption of a gas on solid materials. Langmuir isotherm describes dynamic equilibrium by accounting both the relative rates of adsorption and desorption [57]. The linear form of the Langmuir isotherm model [59] is one of the most widely used isotherm models in the literature.

The simplest form of the isotherm equation is

$C_{\mathrm{e}} / q_{\mathrm{e}}=\left(1 / b q_{\mathrm{m}}\right)+\left(1 / q_{\mathrm{m}}\right) C_{\mathrm{e}}$ 
Table 3 Isotherm parameters for adsorption of Brilliant green (initial concentration range $10-120 \mathrm{mg} \mathrm{L}^{-1}$, $\mathrm{pH}$ 5.4) and Crystal violet (initial concentration range 80-300 $\mathrm{mg} \mathrm{L}^{-1}$, pH 5.9) from aqueous solution on kaolinite and acid-treated clay minerals $\left(2.0 \mathrm{~g} \mathrm{~L}^{-1}\right)$ at $303 \mathrm{~K}$

\begin{tabular}{|c|c|c|c|c|c|c|c|}
\hline \multirow[t]{2}{*}{ Isotherm } & \multirow[t]{2}{*}{ Parameter } & \multicolumn{3}{|c|}{ Brilliant green } & \multicolumn{3}{|c|}{ Crystal violet } \\
\hline & & $\overline{\mathrm{K}}$ & K1 & $\mathrm{K} 2$ & $\overline{\mathrm{K}}$ & K1 & $\mathrm{K} 2$ \\
\hline \multirow[t]{3}{*}{ Freundlich } & $K_{\mathrm{f}}\left(\mathrm{mg}^{1-1 / n} \mathrm{~L}^{1 / n} \mathrm{~g}^{-1}\right)$ & 7.0 & 7.83 & 6.88 & 18.42 & 18.51 & 19.49 \\
\hline & $1 / n$ & 0.33 & 0.29 & 0.33 & 0.17 & 0.17 & 0.17 \\
\hline & $r$ & +0.91 & +0.77 & +0.75 & +0.94 & +0.97 & +0.98 \\
\hline \multirow[t]{3}{*}{ Langmuir } & $q_{\mathrm{m}}\left(\mathrm{mg} \mathrm{g}^{-1}\right)$ & 25.70 & 26.45 & 26.88 & 47.17 & 49.50 & 50.51 \\
\hline & $b\left(\mathrm{~L} \mathrm{mg}^{-1}\right)$ & 0.25 & 0.22 & 0.17 & 0.069 & 0.061 & 0.062 \\
\hline & $r$ & +0.99 & +0.99 & +0.99 & +0.99 & +0.99 & +0.99 \\
\hline \multirow[t]{3}{*}{ Temkin } & $k_{\mathrm{T}}\left(\mathrm{L} \mathrm{mg}^{-1}\right)$ & 4.46 & 6.93 & 3.93 & 6.22 & 5.14 & 6.50 \\
\hline & $B$ & 4.50 & 4.14 & 4.69 & 6.28 & 6.65 & 6.54 \\
\hline & $r$ & +0.98 & +0.88 & +0.89 & +0.94 & +0.97 & +0.97 \\
\hline \multirow[t]{4}{*}{$D-R$} & $q_{\mathrm{s}}\left(\mathrm{mol} \mathrm{g}^{-1}\right)$ & 20.65 & 20.68 & 20.09 & 41.11 & 41.44 & 42.06 \\
\hline & $k_{\mathrm{ad}}\left(\mathrm{mol}^{2} \mathrm{~J}^{-2}\right)$ & $5 \times 10^{-7}$ & $3 \times 10^{-7}$ & $3 \times 10^{-7}$ & $2 \times 10^{-5}$ & $2 \times 10^{-5}$ & $1 \times 10^{-5}$ \\
\hline & $r$ & +0.97 & +0.83 & +0.92 & +0.83 & +0.75 & +0.74 \\
\hline & $E\left(\mathrm{~J} \mathrm{~mol}^{-1}\right)$ & 1000 & 845.15 & 845.15 & 158.11 & 158.11 & 223.61 \\
\hline
\end{tabular}

(a)

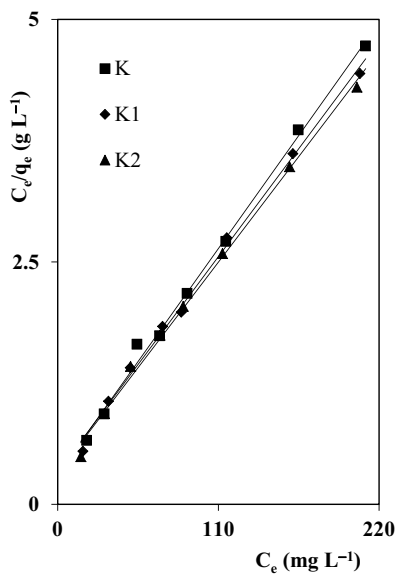

(b)

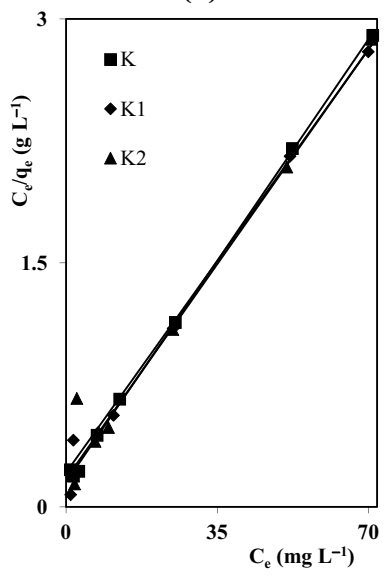

which show a linear relationship between $C_{\mathrm{e}} / q_{\mathrm{e}}$ and $C_{\mathrm{e}} \cdot C_{\mathrm{e}}$ the solution and in the solid, respectively.

The Langmuir coefficient, $q_{m}$, defines the equilibrium adsorption capacity of the solid and the other Langmuir coefficient, $b$, is related to the equilibrium constant of adsorbate-absorbent equilibrium. The coefficients are obtained from the slope and the intercept of the linear plot of $C_{\mathrm{e}} / q_{\mathrm{e}}$ versus $C_{\mathrm{e}}$.

The Langmuir isotherm plots (Fig. 6) for both Brilliant green and Crystal violet had very good linearity ( $r$ : +0.99 ) in all the cases. For Crystal violet, kaolinite and acid-treated kaolinite showed almost double adsorption capacity (47.17-50.51 $\mathrm{mg} \mathrm{g}^{-1}$ ) compare to Brilliant Green $\left(25.7-26.88 \mathrm{mg} \mathrm{g}^{-1}\right)$ at $303 \mathrm{~K}$. For both the adsorption cases, the increase in adsorption capacity was not very large. $0.25 \mathrm{M}$ acid-treated kaolinite showed an increase of $2.92 \%$ (for Brilliant green) and $4.94 \%$ (for crystal violet), whereas $0.50 \mathrm{M}$ acid-treated kaolinite showed $4.59 \%$ (for Brilliant green) and $7.08 \%$ (for Crystal violet) increase in monolayer adsorption capacity compared to that of the parent kaolinite.

The Langmuir equilibrium coefficient, $b$ (Table 3 ) showed higher values for Brilliant green adsorbed in kaolinites $\left(0.17-0.25 \mathrm{~L} \mathrm{mg}^{-1}\right)$ compared to Crystal violet adsorbed in kaolinites $\left(0.061-0.069 \mathrm{~L} \mathrm{mg}^{-1}\right)$, indicating that the Crystal violet-kaolinite adsorption complex was less stable compared to Brilliant green-kaolinite adsorption complex. However, for both the cases, raw kaolinite showed marginally higher $b$ values compared to their acid-treated forms. Table 4 compares the adsorption capacity of some of the adsorbent used for both Brilliant green and Crystal violet. This showed that acid-treated kaolinite can be very useful for the removal of these two cationic dyes from water.
Fig. 6 Langmuir plots for a crystal violet $\left(100 \mathrm{mg} \mathrm{L}^{-1}\right)$ and $\mathbf{b}$ brilliant green $\left(50 \mathrm{mg} \mathrm{L}^{-1}\right)$ on raw and acid-treated kaolinite $\left(2.0 \mathrm{~g} \mathrm{~L}^{-1}\right)$ at $303 \mathrm{~K}$

\subsubsection{Temkin isotherm}

The Temkin isotherm is developed by taking into consideration the effects of adsorbate-adsorbate interactions, and it is based on the assumption that heat of adsorption of all molecules in the layer decreases linearly as surface coverage increases [57]. The model is described by the equation $[65,66]$

$q_{\mathrm{e}}=2.303(R T / b) \log \left(k_{T} C_{\mathrm{e}}\right)$

The linear form of the equation is

$q_{\mathrm{e}}=2.303 B \log k_{T}+2.303 B \log C_{\mathrm{e}}$, where, $B=(R T / b)$ 
Table 4 Comparison of Langmuir adsorption capacity, $q_{\mathrm{m}^{\prime}}\left(\mathrm{mg} \mathrm{g}^{-1}\right)$ for both crystal violet and brilliant green with some other adsorbent

\begin{tabular}{llll}
\hline Dye & Adsorbent & $q_{\mathrm{m}}\left(\mathrm{mg} \mathrm{g}^{-1}\right)$ & References \\
\hline Brilliant green & Nanospinel $\mathrm{Cu}_{x} \mathrm{Mn}_{1-x} \mathrm{Fe}_{2} \mathrm{O}_{4}$ & $0.78-0.86$ & {$[21]$} \\
& Luffa cylindrical sponge & $5.68-18.52$ & {$[60]$} \\
& Modified tannin gel & $8.55-20.41$ & {$[61]$} \\
& Surfactant-modified alumina & 168.59 & {$[27]$} \\
& magnetic composite-materials $\left(\mathrm{Fe}_{3} \mathrm{O}_{4} @ S D B S @ L D H s\right)$ & $340.1-819.6$ & {$[26]$} \\
& Acid-treated kaolinite & $25.70-26.88$ & This study \\
Crystal violet & $44.7-67.1$ & {$[62]$} \\
& Magnetically modified activated carbon & $12.19-13.88$ & {$[63]$} \\
& Moroccan pyrophyllite & 86.54 & {$[24]$} \\
& Tunisian clay & $14.71-17.61$ & {$[64]$} \\
& Modified pea peels & $10.25-150.16$ & {$[25]$} \\
& Bio-molecules composite with peanut hull waste & 254.30 & {$[27]$} \\
& Surfactant-modified alumina & $47.17-50.51$ & This study \\
\hline & Acid-treated kaolinite & &
\end{tabular}

with $k_{T}\left(\mathrm{~L} \mathrm{mg}^{-1}\right)$ being the equilibrium binding constant corresponding to maximum binding energy and $b$ $\left(\mathrm{J} \mathrm{mol}^{-1}\right)$ and $B$ the Temkin coefficients. The dimensionless constant, $B$, is related to the heat of adsorption.

The adsorption data were fitted into the Temkin isotherm plots and the calculated Temkin parameters are shown in Table 3. At $303 \mathrm{~K}$, the Temkin isotherm plots $\left(q_{\mathrm{e}}\right.$ vs. $\log C_{\mathrm{e}}$ ) for adsorption of Brilliant Green and Crystal violet on kaolinite clay minerals were linear with high regression coefficient $(r:+0.88$ to +0.98$)$. For both the cases, $k_{T}$ did not follow any particular trends. A higher value of ' $B$ ' for Crystal violet showed that this interaction has a higher heat of adsorption compared to Brilliant green adsorption.

\subsubsection{Dubinin-Radushkevich (D-R) isotherm model}

D-R isotherm [67] model was first used to explain the adsorption of subcritical vapor into micro-porous solid. This model is generally used to describe the adsorption happening on a heterogeneous surface that has Gaussian energy distribution $[68,69]$. Both physical and chemical adsorption process can be verified by calculating mean sorption energy from $D-R$ isotherm.

The linear form of the $D-R$ isotherm can be represented as

$\ln \left(q_{\mathrm{e}}\right)=\ln \left(q_{\mathrm{s}}\right)-k_{\mathrm{ad}} \varepsilon^{2}$

where $q_{\mathrm{s}}$ is the theoretical saturation capacity $\left(\mathrm{mol} \mathrm{g}^{-1}\right)$. The parameter $k_{\text {ad }}$ is Dubinin-Radushkevich isotherm constant $\left(\mathrm{mol}^{2} \mathrm{~J}^{-2}\right)$. The parameter $\varepsilon$ can be correlated as:

$\varepsilon=R T \ln \left(1+1 / C_{\mathrm{e}}\right)$

where, $R, T$, and $C_{\mathrm{e}}$ represent the gas constant $\left(8.314 \mathrm{~J} \mathrm{~mol}^{-1} \mathrm{~K}^{-1}\right)$, temperature $(\mathrm{K})$ and adsorbate equilibrium concentration $\left(\mathrm{mg} \mathrm{L}^{-1}\right)$, respectively [70]. The plot of $\ln q_{\mathrm{e}}$ versus $\varepsilon^{2}$ gave straight lines, from which the values of $q_{s}$ and $k_{\text {ad }}$ could be determined from the intercept and slope. The mean sorption energy, $E$, which was the free energy of transfer of $1 \mathrm{~mol}$ of solute, from infinity (bulk solution) to the surface of adsorbent is given by [71]

$E=1 /\left(-2 k_{\mathrm{ad}}\right)^{0.5}$

The $E\left(\mathrm{k} \mathrm{J} \mathrm{mol}^{-1}\right)$ value provides information about adsorption type. If the value lies between 8 and $16 \mathrm{~kJ} \mathrm{~mol}^{-1}$, the adsorption process is described as chemical and if it is less than $8 \mathrm{k} \mathrm{J} \mathrm{mol}^{-1}$, the process is depicted as physical.

At $303 \mathrm{~K}$, the calculated D-R isotherm parameters are shown in Table 3. The theoretical saturation capacities $\left(q_{s}\right)$ for Crystal violet was almost double than that of Brilliant green dye, which was similar to the trends of Langmuir isotherm. The mean adsorption energy was in the range of (158.11-1000.00 $\mathrm{J} \mathrm{mol}^{-1}$, Table 3), suggesting physisorption to be the most viable path for adsorption of both Brilliant green and Crystal violet on kaolinite and acid-treated kaolinite. $\mathrm{D}-\mathrm{R}$ isotherm was poorly fitted to the adsorption process with regression coefficient, $r$, ranging from +0.83 to +0.97 for Brilliant green and +0.74 to +0.83 for Crystal violet.

\subsubsection{Adsorption mechanism}

Acid treatment has increased the zero point charge of kaolinite from $\mathrm{pH} 2.9$ to 4.0 and 4.2, respectively, for $\mathrm{K}, \mathrm{K} 1$, and $\mathrm{K} 2$. Since all the experiments in this study were carried out with as-prepared aqueous solution of the dyes, it is likely that the dye molecules were exposed to a negatively charged clay mineral surfaces. As both Brilliant green and Crystal violet were cationic in nature, it is likely that both the dye molecule bind the clay mineral surface through electrostatic interaction. However, this interaction was probably weak due to the fact that the adsorption process 
was most likely to be physisorption as suggested by the mean sorption energy, $E$ (calculated from $D-R$ isotherm).

The presence of new FTIR peaks (Fig S5 in SI) due to skeletal vibration representing $\mathrm{C}=\mathrm{C}$ stretching (1419, $\left.1458,1560 \mathrm{~cm}^{-1}\right)$, aromatic $\mathrm{C}-\mathrm{N}$ stretching $\left(1374 \mathrm{~cm}^{-1}\right)$ and $\mathrm{CH}_{2}$ twisting $\left(1300 \mathrm{~cm}^{-1}\right)$ proved that the presence of the dye molecules on the surface of kaolinite after adsorption. The adsorption shifted the $-\mathrm{OH}$ stretching (3618 and $3695 \mathrm{~cm}^{-1}$ ), O-Si-O stretching $(1006,1029$ and $1114 \mathrm{~cm}^{-1}$ ) and $\mathrm{Si}-\mathrm{O}$ bending vibrations (Table S6, in SI) for both the dyes. The most affected bands were the two $-\mathrm{OH}$ stretching band in the raw kaolinite, which merged into one with shifting after adsorption of the dye. This suggested that $-\mathrm{OH}$ and $-\mathrm{O}$ - sites were most likely to interact with the dye molecules in both the cases. In this study, Crystal violet showed almost double the adsorption capacities compared to Brilliant green. This could be explained by the size of the dye molecules as obtained by structural optimization using Gaussian 09 program package. It is likely that the bigger dimension of Brilliant green $(16.185 \times 5.957 \times 12.324)$ compared to Crystal violet $(13.916 \times 4.132 \times 13.916)$ prevented them to come within the active sites of the kaolinite surface and hence could not occupy the pores effectively. Furthermore, the three possible binding sites ( $\mathrm{N}$ atom) in Crystal violet compared to two binding sites ( $\mathrm{N}$ atom) in Brilliant green help Crystal violet to be adsorbed more in kaolinite by electrostatic interaction. Similar shifting of FTIR peaks was also reported by Auta and Hameed [72] for adsorption of Methylene blue on raw and modified ball clay. Dhananasekaran et al. [73] also observed some small but significant shifting in peak values for the adsorption of Methylene blue, Bromophenol blue and Coomassie brilliant blue by chitin nanoparticles, and they also concluded that these were the result of physical interaction between the dyes and $a$-chitin nanoparticles.

\subsection{Thermodynamics of adsorption}

The effects of temperature (293-323 K) on adsorption of Brilliant green and Crystal violet on $\mathrm{K}, \mathrm{K} 1$, and $\mathrm{K} 2$ are shown in Fig. 7. In this temperature range, the extent of adsorption of Brilliant green dye increased slightly from $4.97 \%$ for K to $6.0 \%$ (K1) and $11.6 \%$ (K2). However, Crystal violet showed an opposite trend and the adsorption decreased by $24.28,17.81$ and $23.80 \%$, respectively, for K, $\mathrm{K} 1$, and $\mathrm{K} 2$.

The thermodynamic parameters of Gibbs energy $(\Delta G)$, enthalpy $(\Delta H)$ and entropy $(\Delta S)$ of adsorption are computed from the data generated by carrying out the dye adsorption process at several temperatures. The thermodynamic adsorption parameters, $\Delta H, \Delta S$, and $\Delta G$, were computed (Table S7, in SI) from the plots of log $K_{d}$ versus $1 / T$ using the equations

$\log K_{\mathrm{d}}=\Delta S / 2.303 R-\Delta H / 2.303 R T$

$\Delta G=\Delta H-T \Delta S$

where $K_{\mathrm{d}}\left(=q_{\mathrm{e}} / C_{\mathrm{e}}\right)$ is known as the distribution coefficient, $\mathrm{T}$ is the temperature $(\mathrm{K})$, and $\mathrm{R}=8.314 \times 10^{-3} \mathrm{~kJ} \mathrm{~K}^{-1} \mathrm{~mol}^{-1}$. The mean adsorption enthalpy, $\Delta H$, for Brilliant green and Crystal violet, ranges from 8.91 to $15.81 \mathrm{~kJ} \mathrm{~mol}^{-1}$ and -12.45 to $-16.25 \mathrm{~kJ} \mathrm{~mol}^{-1}$, respectively (Table S7, in SI). The low values indicate that the dye cations are held to the clay surface by comparatively weak forces not amounting to the formation of strong covalent bonds.

The negative values for $\Delta S$ in case of Crystal violet suggested that exothermic adsorption of Crystal violet was accompanied by a decrease in entropy, and this shows that the dye molecules are held to the clay mineral surface in some sort of order compared to their distribution in the liquid phase. The same cannot be said for Brilliant green as the process is endothermic with the increased disorder after adsorption.

Gibbs energy, $\Delta G$ is $<0$ for Brilliant green, indicating that the adsorption process was spontaneous in the temperature range of 293 to $323 \mathrm{~K}$. On the other hand, for Crystal violet dye, $\Delta G$ is $>0$, indicating a non-spontaneous adsorption. However, with an increase in temperature, $\Delta G$ showed an increasing trend, showing at a sufficiently lower temperature the adsorption process could be spontaneous.

\subsection{Reusability of the prepared adsorbents}

The reusability of the adsorbents was examined for removal of dye molecules for five consecutive adsorption-desorption cycles. Each time after adsorption, (a)

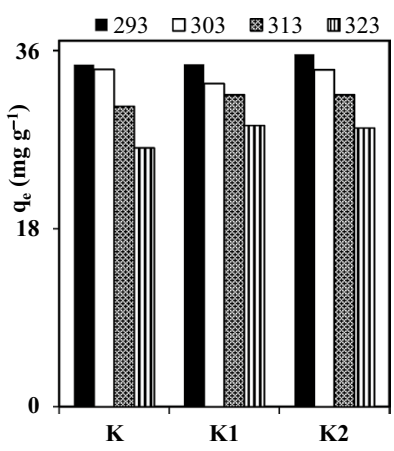

(b)

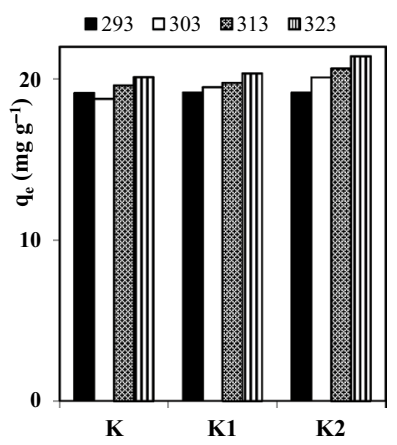

Fig. 7 Influence of temperature for adsorption of a crystal violet (100 $\left.\mathrm{mg} \mathrm{L}^{-1}\right)$ and $\mathbf{b}$ brilliant green $\left(50 \mathrm{mg} \mathrm{L}^{-1}\right)$ on raw and acidtreated kaolinite $\left(2.0 \mathrm{~g} \mathrm{~L}^{-1}\right)$ at $303 \mathrm{~K}$ 
the adsorbent was isolated by centrifugation and was dispersed in $10 \mathrm{~mL} 0.1 \mathrm{M} \mathrm{H}_{2} \mathrm{SO}_{4}$ and shaken in a shaker for $5 \mathrm{~min}$ followed by ultrasonic vibration for $15 \mathrm{~min}$ to remove the adsorbed dye molecules and then again centrifuged to isolate the solid adsorbent. The process was repeated for three times, and finally, the isolated solid was used for another batch of adsorption. It was observed that, realistically, kaolinite and acid-treated kaolinite can be reused for three cycles; after that a significant decrease in adsorption capacity was observed (Fig. 8).

For Crystal violet, all the clay minerals, namely, K, K1, and $\mathrm{K} 2$, showed almost steady adsorption with only $1.3 \%$, $2.2 \%$, and $2.2 \%$ decrease, respectively, between the first and third cycle. However, in the 5th cycle, adsorption decreased significantly up to $8.0 \%, 9.9 \%$, and $10.8 \%$, respectively, for $\mathrm{K}, \mathrm{K} 1$, and $\mathrm{K} 2$. In case of Brilliant green, the extent of adsorption decreased gradually from 1 st to 5 th cycle. The decrease between 1st and 3rd cycle was 3.1\%, $2.3 \%$, and $3.6 \%$, respectively, for $\mathrm{K}, \mathrm{K} 1$, and $\mathrm{K} 2$. In the 5 th cycle, K, K1, and $K 2$ showed almost $~ 6 \%$ decrease in the adsorption of brilliant green.

The reusability study specified that the natural and acid activated kaolinite clays can be used for these dye adsorption purposes even up to 5 th adsorption-desorption cycle, indicating the cost effectiveness of these adsorbents.

\section{Conclusion}

Herein, we report adsorption of two cationic dyes with the help of kaolinite and its acid-treated form from the water. Acid treatment did not show any adverse effect on the structure of the kaolinite clay mineral and it remained mostly intact. Acid treatment helped in removing the (a)

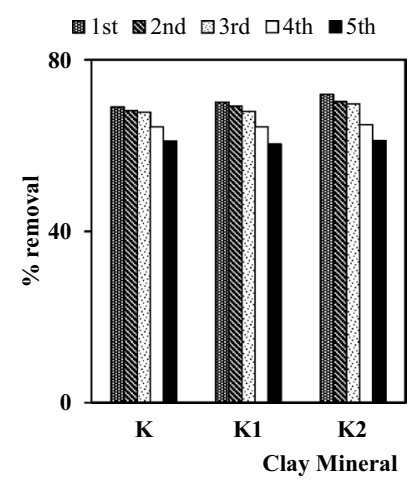

(b)

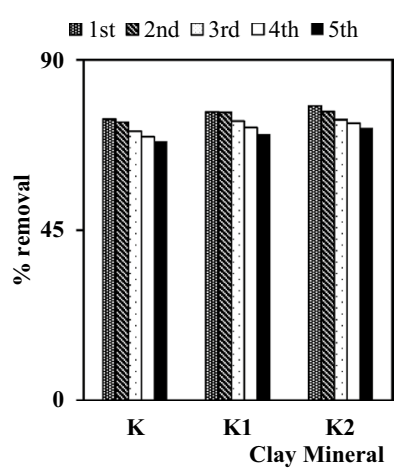

Fig. 8 Bar diagram showing a variation of \% removal of a crystal violet $\left(100 \mathrm{mg} \mathrm{L}^{-1}\right)$ and $\mathbf{b}$ brilliant green $\left(50 \mathrm{mg} \mathrm{L}^{-1}\right)$ on raw and acid-treated kaolinite $\left(2.0 \mathrm{~g} \mathrm{~L}^{-1}\right)$ at $303 \mathrm{~K}$ for 1 st to 5 th cycle surface impurities and increasing the surface area along with pore volume and CEC of the kaolinite clay mineral.

Both the adsorption processes were fast and showed a good fit to pseudo-second-order kinetics among the studied models. The Langmuir isotherm showed the best fit to the adsorption equilibrium data. The Langmuir adsorption capacities for Brilliant green and Crystal violet were recorded to be 25.70 and $47.17 \mathrm{mg} \mathrm{g}^{-1}$, respectively, which increased to 26.45 and $26.88 \mathrm{mg} \mathrm{g}^{-1}$ for Brilliant green and 49.50 and $50.51 \mathrm{mg} \mathrm{g}^{-1}$ for Crystal violet after acid treatment of kaolinite with $0.25 \mathrm{M}$ and $0.50 \mathrm{M}$ acid at $303 \mathrm{~K}$. The thermodynamic studies revealed Brilliant green adsorption process to be endothermic, whereas Crystal violet adsorption process to be exothermic. Gibbs energy, $\Delta G$ is $<0$ for Brilliant green, indicating that the adsorption process was spontaneous in the temperature range of $293-323 \mathrm{~K}$. The Crystal violet showed $\Delta G>0$, but the values were very low and low temperature favored this adsorption. The adsorption mechanism is likely to be electrostatic interaction between negatively charged clay mineral surface and the cationic dye molecules. Also, the dye molecular size does play a role in the adsorption process. The reusability of the material showed that kaolinite and acid-treated kaolinite can be successfully used to remove cationic dyes, namely Crystal violet and Brilliant green from the water.

Acknowledgements The authors are grateful to the University Grants Commission, New Delhi, for providing assistance under a Major Research Project for this work. Authors offer thanks to IIT Guwahati, SIF, Gauhati University, and IASST, Guwahati, for help in taking SEM, $\mathrm{XRD}$ and zeta potential measurements, respectively, of the clays.

\section{Compliance with ethical standards}

Conflict of interest The authors declare that they have no competing interests.

\section{References}

1. Tan KB, Vakili M, Horri BA, Poh PE, Abdullah AZ, Salamatinia B (2015) Adsorption of dyes by nanomaterials: recent developments and adsorption mechanisms. Sep Purif Technol 150:229242. https://doi.org/10.1016/j.seppur.2015.07.009

2. Mittal A, Kaur D, Mittal J (2008) Applicability of waste materialsbottom ash and deoiled soya-as adsorbents for the removal and recovery of a hazardous dye, brilliant green. J Colloid Interf Sci 326:8-17. https://doi.org/10.1016/j.jcis.2008.07.005

3. Tian G, Wang W, Kang Y, Wang A (2016) Ammonium sulfideassisted hydrothermal activation of palygorskite for enhanced adsorption of methyl violet. J Environ Sci 41:33-43. https://doi. org/10.1016/j.jes.2015.03.036

4. Yu J-X et al (2015) Synergistic and competitive adsorption of cationic and anionic dyes on polymer modified yeast prepared at room temperature. J Taiwan Inst Chem E 57:98-103. https:// doi.org/10.1016/j.jtice.2015.05.018 
5. Kismir Y, Aroguz AZ (2011) Adsorption characteristics of the hazardous dye Brilliant green on Saklıkent mud. Chem Eng J 172:199-206. https://doi.org/10.1016/j.cej.2011.05.090

6. Makhoukhi B, Djab M, Amine Didi M (2015) Adsorption of Telon dyes onto bis-imidazolium modified bentonite in aqueous solutions. J Environ Chem Eng 3:1384-1392. https://doi. org/10.1016/j.jece.2014.12.012

7. Sharma P, Kaur H, Sharma M, Sahore V (2011) A review on applicability of naturally available adsorbents for the removal of hazardous dyes from aqueous waste. Environ Monit Assess 183:151-195. https://doi.org/10.1007/s10661-011-1914-0

8. Srinivasan R (2011) Advances in application of natural clay and its composites in removal of biological, organic, and inorganic contaminants from drinking water. Adv Mater Sci Eng. Article ID 872531. https://doi.org/10.1155/2011/872531

9. Zhou CH, Keeling J (2013) Fundamental and applied research on clay minerals: from climate and environment to nanotechnology. Appl Clay Sci 74:3-9. https://doi.org/10.1016/j. clay.2013.02.013

10. Pauling $L$ (1930) The structure of the micas and related minerals. Proc Natl Acad Sci USA 16:123-129

11. Gruner JW (1932) The crystal structure of kaolinite Zeitschrift für Kristallographie. Cryst Mater 83:75-80

12. Brigatti MF, Galan E, Theng BKG (2006) Chapter 2 structures and mineralogy of clay minerals. In: Bergaya F, Theng BKG, Lagaly $\mathrm{G}$ (eds) Developments in clay science, vol 1. Elsevier, pp 19-86. https://doi.org/10.1016/S1572-4352(05)01002-0

13. Khan TA, Khan EA, Shahjahan (2015) Removal of basic dyes from aqueous solution by adsorption onto binary iron-manganese oxide coated kaolinite: non-linear isotherm and kinetics modeling. Appl Clay Sci 107:70-77. https://doi.org/10.1016/j. clay.2015.01.005

14. Khan TA, Dahiya S, Khan EA (2017) Removal of Direct red 81 from aqueous solution by adsorption onto magnesium oxidecoated kaolinite: isotherm, dynamics and thermodynamic studies. Environ Prog Sustain Energy 36:45-58. https://doi. org/10.1002/ep.12432

15. Zhang Q, Yan Z, Ouyang J, Zhang Y, Yang H, Chen D (2018) Chemically modified kaolinite nanolayers for the removal of organic pollutants. Appl Clay Sci 157:283-290. https://doi. org/10.1016/j.clay.2018.03.009

16. De Castro MLFA, Abad MLB, Sumalinog DAG, Abarca RRM, Paoprasert P, de Luna MDG (2018) Adsorption of Methylene blue dye and $\mathrm{Cu}(\mathrm{II})$ ions on EDTA-modified bentonite: isotherm, kinetic and thermodynamic studies. Sustain Environ Res 28:197-205. https://doi.org/10.1016/j.serj.2018.04.001

17. Sarma GK, SenGupta S, Bhattacharyya KG (2011) Methylene blue adsorption on natural and modified clays. Sep Sci Technol 46:1602-1614. https://doi.org/10.1080/01496 395.2011.565012

18. Bhattacharyya KG, SenGupta S, Sarma GK (2015) Kinetics, equilibrium isotherms and thermodynamics of adsorption of Congo red onto natural and acid-treated kaolinite and montmorillonite. Desalin Water Treat 53:530-542. https://doi.org/10.1080/19443 994.2013.839405

19. Bhattacharyya KG, SenGupta S, Sarma GK (2014) Interactions of the dye, Rhodamine $B$ with kaolinite and montmorillonite in water. Appl Clay Sci 99:7-17. https://doi.org/10.1016/j. clay.2014.07.012

20. Gholami M, Vardini MT, Mahdavinia GR (2016) Investigation of the effect of magnetic particles on the Crystal violet adsorption onto a novel nanocomposite based on K-carrageenan-gpoly(methacrylic acid). Carbohyd Polym 136:772-781. https:// doi.org/10.1016/j.carbpol.2015.09.044

21. Hashemian S, Dehghanpor A, Moghahed M (2015) $\mathrm{Cu} 0.5 \mathrm{Mn} 0.5 \mathrm{Fe}_{2} \mathrm{O}_{4}$ nano spinels as potential sorbent for adsorption of brilliant green. J Ind Eng Chem 24:308-314. https ://doi.org/10.1016/j.jiec.2014.10.001

22. Kakhki RMZ, Heydari S (2014) A simple conductometric method for trace level determination of Brilliant green in water based on $\beta$-cyclodextrin and silver nitrate and determination of their thermodynamic parameters. Arab J Chem 7:1086-1090. https ://doi.org/10.1016/j.arabjc.2011.09.016

23. Oplatowska M, Donnelly RF, Majithiya RJ, Glenn Kennedy D, Elliott CT (2011) The potential for human exposure, direct and indirect, to the suspected carcinogenic triphenylmethane dye Brilliant Green from green paper towels. Food Chem Toxicol 49:1870-1876. https://doi.org/10.1016/j.fct.2011.05.005

24. Hamza W, Dammak N, Hadjltaief HB, Eloussaief M, Benzina M (2018) Sono-assisted adsorption of Cristal violet dye onto Tunisian smectite clay: characterization, kinetics and adsorption isotherms. Ecotoxicol Environ Saf 163:365-371. https://doi. org/10.1016/j.ecoenv.2018.07.021

25. Tahir N, Bhatti HN, lqbal M, Noreen S (2017) Biopolymers composites with peanut hull waste biomass and application for Crystal violet adsorption. Int J Biol Macromol 94:210-220. https ://doi.org/10.1016/j.ijbiomac.2016.10.013

26. Zhang D, Zhu M-y Yu, J-g Meng H-w, F-p Jiao (2017) Effective removal of Brilliant green from aqueous solution with magnetic $\mathrm{Fe}_{3} \mathrm{O}_{4} @ \mathrm{SDBS} @ L D H s$ composites. Trans Nonferrous Met Soc China 27:2673-2681. https://doi.org/10.1016/s1003 $-6326(17) 60296-6$

27. Zolgharnein J, Bagtash M, Shariatmanesh T (2015) Simultaneous removal of binary mixture of Brilliant green and Crystal violet using derivative spectrophotometric determination, multivariate optimization and adsorption characterization of dyes on surfactant modified nano-gamma-alumina. Spectrochim Acta A Mol Biomol Spectrosc 137:1016-1028. https://doi.org/10.1016/j. saa.2014.08.115

28. Espantaleón AG, Nieto JA, Fernández M, Marsal A (2003) Use of activated clays in the removal of dyes and surfactants from tannery waste waters. Appl Clay Sci 24:105-110. https://doi. org/10.1016/S0169-1317(03)00153-4

29. Frisch MJ et al. (2016):Gaussian 09, Revision B.01, Gaussian, Inc., Wallingford CT

30. Sarma GK, SenGupta S, Bhattacharyya KG (2016) Adsorption of Crystal violet on raw and acid-treated montmorillonite, $\mathrm{K} 10$, in aqueous suspension. J Environ Manag 171:1-10. https://doi. org/10.1016/j.jenvman.2016.01.038

31. Nguetnkam JP, Kamga R, Villiéras F, Ekodeck GE, Razafitianamaharavo A, Yvon J (2011) Alteration of cameroonian clays under acid treatment. Comparison with industrial adsorbents. Appl Clay Sci 52:122-132. https://doi.org/10.1016/j.clay.2011.02.009

32. Panda AK, Mishra BG, Mishra DK, Singh RK (2010) Effect of sulphuric acid treatment on the physico-chemical characteristics of kaolin clay. Colloid Surf A 363:98-104. https://doi.org/10.1016/j. colsurfa.2010.04.022

33. Wu P, Ming C (2006) The relationship between acidic activation and microstructural changes in montmorillonite from Heping, China. Spectrochim Acta A 63:85-90. https://doi.org/10.1016/j. saa.2005.04.050

34. Liu Z-L, Deng J-C, Deng J-J, Li F-F (2008) Fabrication and photocatalysis of $\mathrm{CuO} / \mathrm{ZnO}$ nano-composites via a new method. Mater Sci Eng, B 150:99-104. https://doi.org/10.1016/j. mseb.2008.04.002

35. Madejová J (2003) FTIR techniques in clay mineral studies. Vib Spectrosc 31:1-10. https://doi.org/10.1016/S0924 -2031(02)00065-6

36. Monash P, Niwas R, Pugazhenthi G (2011) Utilization of ball clay adsorbents for the removal of crystal violet dye from aqueous solution. Clean Technol Environ 13:141-151. https://doi. org/10.1007/s10098-010-0292-6 
37. Hassanien MM, Abou-El-Sherbini KS, Al-Muaikel NS (2010) Immobilization of methylene blue onto bentonite and its application in the extraction of mercury (II). J Hazard Mater 178:94-100. https://doi.org/10.1016/j.jhazmat.2010.01.048

38. Temuujin J, Jadambaa T, Burmaa G, Erdenechimeg S, Amarsanaa J, MacKenzie KJD (2004) Characterisation of acid activated montmorillonite clay from Tuulant (Mongolia). Ceram Int 30:251-255. https://doi.org/10.1016/S0272-8842(03)00096 $-8$

39. Madejová J, Bujdák J, Janek M, Komadel P (1998) Comparative FT-IR study of structural modifications during acid treatment of dioctahedral smectites and hectorite Spectrochim Acta A 54:1397-1406. https://doi.org/10.1016/S1386-1425(98)00040 $-7$

40. Galan E, Aparicio P, Miras A, Michailidis K, Tsirambides A (1996) Technical properties of compounded kaolin sample from Griva (Macedonia, Greece). Appl Clay Sci 10:477-490. https://doi. org/10.1016/0169-1317(95)00041-0

41. Unuabonah El, Adebowale KO, Dawodu FA (2008) Equilibrium, kinetic and sorber design studies on the adsorption of Aniline blue dye by sodium tetraborate-modified Kaolinite clay adsorbent. J Hazard Mater 157:397-409. https://doi.org/10.1016/j. jhazmat.2008.01.047

42. Sing KSW, Everett DH, Haul RAW, Moscou L, Pierotti RA, Rouquérol J, Siemieniewska T (1985) Reporting physisorption data for gas/solid systems with special reference to the determination of surface area and porosity. Pure Appl Chem 57:603-619

43. Koyuncu H, Kul AR, Yıldız N, Çalımlı A, Ceylan H (2007) Equilibrium and kinetic studies for the sorption of 3-methoxybenzaIdehyde on activated kaolinites. J Hazard Mater 141:128-139. https://doi.org/10.1016/j.jhazmat.2006.06.101

44. Gao W, Zhao S, Wu H, Deligeer W, Asuha S (2016) Direct acid activation of kaolinite and its effects on the adsorption of Methylene blue. Appl Clay Sci 126:98-106. https://doi.org/10.1016/j. clay.2016.03.006

45. Torres-Luna JA, Carriazo JG (2019) Porous aluminosilicic solids obtained by thermal-acid modification of a commercial kaolinite-type natural clay. Solid State Sci 88:29-35. https://doi. org/10.1016/j.solidstatesciences.2018.12.006

46. Aljeboree AM, Alshirifi AN, Alkaim AF (2017) Kinetics and equilibrium study for the adsorption of textile dyes on coconut shell activated carbon. Arab J Chem 10:S3381-S3393. https://doi. org/10.1016/j.arabjc.2014.01.020

47. Lagergren S (1898) About the theory of so-called adsorption of soluble substances. Kungliga Svenska Vetenskapsakademiens Handlingar 24:1-39

48. Ho YS, McKay G (1998) A comparison of chemisorption kinetic models applied to pollutant removal on various sorbents. Process Saf Environ 76:332-340. https://doi.org/10.1205/09575 8298529696

49. Ho YS, McKay G (1999) Pseudo-second order model for sorption processes. Process Biochem 34:451-465. https://doi. org/10.1016/S0032-9592(98)00112-5

50. Weber WJ Jr, Morris JC (1963) Kinetics of adsorption on carbon from solution. J Sanit Eng Div ASCE 89(SA2):31-59

51. Boyd GE, Adamson AW, Myers LS (1947) The exchange adsorption of ions from aqueous solutions by organic zeolites. II. Kinetics. J Am Chem Soc 69:2836-2848. https://doi.org/10.1021/ja012 $03 \mathrm{a} 066$

52. Ghaedi M, Hossainian $H$, Montazerozohori $M$, Shokrollahi $A$, Shojaipour F, Soylak M, Purkait MK (2011) A novel acorn based adsorbent for the removal of brilliant green. Desalination 281:226-233. https://doi.org/10.1016/j.desal.2011.07.068

53. Rudzinski W, Panczyk T (2002) The Langmuirian adsorption kinetics revised: a farewell to the XXth century theories? Adsorption 8:23-34. https://doi.org/10.1023/A:1015214406179
54. SenGupta S, Bhattacharyya KG (2011) Kinetics of adsorption of metal ions on inorganic materials: a review. Adv Colloid Interf 162:39-58. https://doi.org/10.1016/j.cis.2010.12.004

55. Zhang SQ, Hou WG (2008) Adsorption behavior of Pb(II) on montmorillonite. Colloid Surf A 320:92-97. https://doi. org/10.1016/j.colsurfa.2008.01.038

56. Tan IAW, Hameed BH (2010) Adsorption isotherms, kinetics, thermodynamics and desorption studies of Basic dye on activated carbon derived from oil palm empty fruit bunch. J Appl Sci 10:2565-2571

57. Ayawei N, Ebelegi AN, Wankasi D (2017) Modelling and interpretation of adsorption isotherms. J Chem. Article ID 3039817. https://doi.org/10.1155/2017/3039817

58. Freundlich HMF (1906) Over the adsorption in solution. J Phys Chem 57:385-471

59. Langmuir I (1916) The constitution and fundamental properties of solids and liquids. Part I. Solids J Am Chem Soc 38:2221-2295. https://doi.org/10.1021/ja02268a002

60. Esan OS, Abiola ON, Owoyomi O, Aboluwoye CO, Osundiya MO (2014) Adsorption of Brilliant green onto Luffa Cylindrical sponge: equilibrium, kinetics, and thermodynamic studies. ISRN Phys Chem. Article ID 743532:1-12. http://dx.doi. org/10.1155/2014/743532

61. Akter $\mathrm{N}$ et al (2016) Amine modified tannin gel for adsorptive removal of Brilliant green dye. J Environ Chem Eng 4:12311241. https://doi.org/10.1016/j.jece.2016.01.013

62. Hamidzadeh S, Torabbeigi M, Shahtaheri SJ (2015) Removal of Crystal violet from water by magnetically modified activated carbon and nanomagnetic iron oxide. J Environ Health Sci Eng 13:8. https://doi.org/10.1186/s40201-015-0156-4

63. Miyah $Y$, Lahrichi A, Idrissi M, Boujrafc Sd, Taouda H, Zerrouq F (2017) Assessment of adsorption kinetics for removal potential of Crystal violet dye from aqueous solutions using Moroccan pyrophyllite. J Assoc Arab Univ Basic Appl Sci 23:20-28. https://doi.org/10.1016/j.jaubas.2016.06.001

64. Khan TA, Rahman R, Khan EA (2016) Decolorization of Bismarck brown $\mathrm{R}$ and Crystal violet in liquid phase using modified pea peels: non-linear isotherm and kinetics modeling. Model Earth Syst Environ 2:141. https://doi.org/10.1007/s4080 8-016-0195-6

65. Ahmad A, Rafatullah $\mathrm{M}$, Sulaiman $\mathrm{O}$, Ibrahim $\mathrm{MH}$, Hashim $\mathrm{R}$ (2009) Scavenging behaviour of meranti sawdust in the removal of Methylene blue from aqueous solution. J Hazard Mater 170:357-365. https://doi.org/10.1016/j.jhazmat.2009.04.087

66. Mane VS, Babu PVV (2011) Studies on the adsorption of Brilliant green dye from aqueous solution onto low-cost $\mathrm{NaOH}$ treated saw dust. Desalination 273:321-329. https://doi.org/10.1016/j. desal.2011.01.049

67. Dubinin MM, Radushkevich LV (1947) The equation of the characteristic curve of the activated charcoal. Proc Acad Sci Phys Chem Sect USSR 55:331-337

68. Dąbrowski A (2001) Adsorption-from theory to practice. Adv Colloid Interf 93:135-224. https://doi.org/10.1016/S0001 $-8686(00) 00082-8$

69. Günay A, Arslankaya E, Tosun I (2007) Lead removal from aqueous solution by natural and pretreated clinoptilolite: adsorption equilibrium and kinetics. J Hazard Mater 146:362-371. https:// doi.org/10.1016/j.jhazmat.2006.12.034

70. Foo KY, Hameed BH (2010) Insights into the modeling of adsorption isotherm systems. Chem Eng J 156:2-10. https://doi. org/10.1016/j.cej.2009.09.013

71. Mufazzal Saeed M, Ghaffar A (1998) Adsorption syntax of $\mathrm{Au}$ (III) on unloaded polyurethane foam. J Radioanal Nucl Chem 232:171-177. https://doi.org/10.1007/bf02383736

72. Auta M, Hameed BH (2012) Modified mesoporous clay adsorbent for adsorption isotherm and kinetics of Methylene blue. 
Chem Eng J 198-199:219-227. https://doi.org/10.1016/j. cej.2012.05.075

73. Dhananasekaran S, Palanivel R, Pappu S (2016) Adsorption of Methylene blue, Bromophenol blue, and Coomassie brilliant blue by a-chitin nanoparticles. J Adv Res 7:113-124. https:// doi.org/10.1016/j.jare.2015.03.003
Publisher's Note Springer Nature remains neutral with regard to jurisdictional claims in published maps and institutional affiliations. 